\title{
Retraction Note to: Management of the large septal perforations with the support of porous high-density polyethylene (MEDPOR)
}

\author{
Ilteris Murat Emsen ${ }^{1,2}$ \\ (C) Springer-Verlag GmbH Germany, part of Springer Nature 2019
}

Retraction Note to: Eur J Plast Surg (2007) 29:277-283

https://doi.org/10.1007/s00238-006-0103-9

The Editor-in-Chief has retracted this article [1] because significant parts of the text and Figs. 1 to 6 and 7a were duplicated from a previously published article by Romo et al [2]. Additionally, Figs. $7 \mathrm{~b}$ to $7 \mathrm{~h}$ have been removed because the author did not obtain written consent to publish from the patients shown. The author agrees with this retraction.

\section{References}

1. Emsen, I. Eur J Plast Surg (2007) Management of the large septal perforations with the support of porous high-density polyethylene (MEDPOR) 29: 277. https://doi.org/10.1007/s00238-006-0103-9

2. Romo T, Sclafani A, Falk A, Toffel PA (1999) Graduated approach to the repair of nasal septal perforations. Plast Reconstr Surg 103: 66-75.

The online version of the original article can be found at https://doi.org/ 10.1007/s00238-006-0103-9

Ilteris Murat Emsen

ilterisemsen@hotmail.com

1 Department of Plastic, Reconstructive and Aesthetic Surgery,

Numune State Hospital, Erzurum, Turkey

2 Ataturk Universitesi Lohmanlari, Erzurum, Turkey 


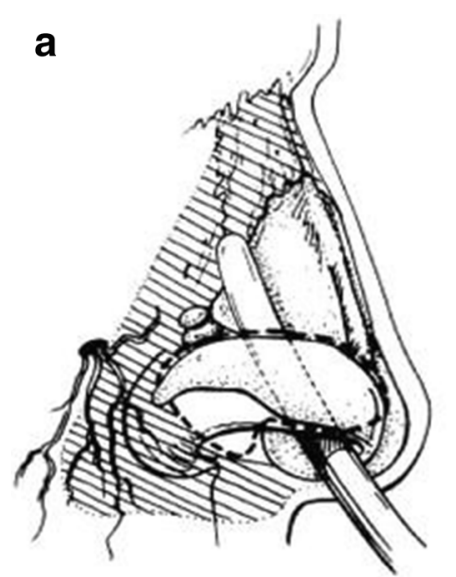

b
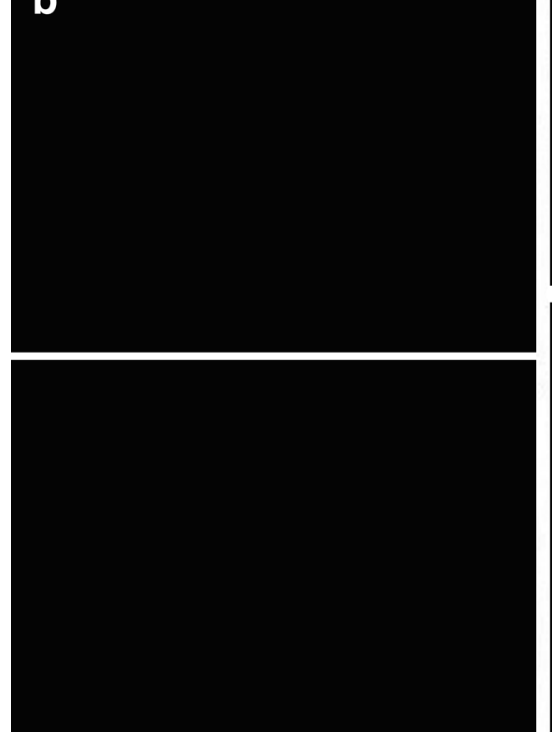
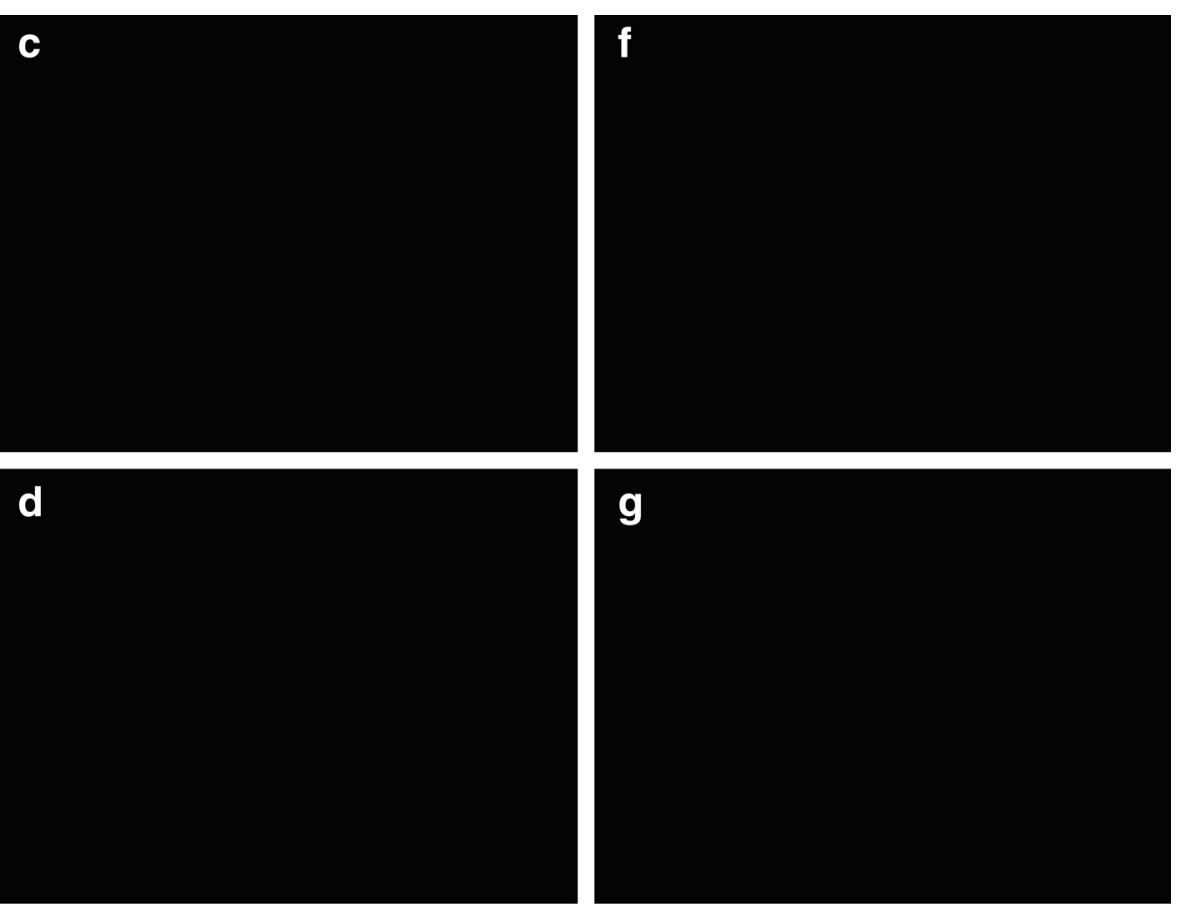

e

h 